\title{
Entrevista
}

\section{Una carta a la besàvia: continguts, reflexió i sistematització a la classe de llengua. Algunes de les claus del treball per projectes. Entrevista amb Mercè Canals i Palau}

\author{
Aida Guillén Onandia \\ Universitat Autònoma de Barcelona, Barcelona
}

Versió final rebuda el 1 d'agost de 2013

\begin{abstract}
Mercè Canals és catedràtica de Llengua i Literatura Catalanes a l'INS Lluís Companys de Ripollet, on és Cap del Departament de Llengua Catalana. Ha publicat articles en Perspectiva escolar (Canals i Palau, 2007a, 2007b) i ha participat com a ponent en les I, II i III Jornades per a docents de llengua $i$ literatura organitzades per l'ICE de la UAB els anys 2010, 2011 i 2013. Forma part de l'Equip de Llengua de Secundària de l'ICE de la UAB i ha estat guanyadora del primer premi de la Fundación Telefónica de Innovación Educativa 2012 amb el projecte Estimada besàvia. Una carta gairebé impossible ${ }^{1}$. En aquesta entrevista parla sobre la seva experiència $i$ ofereix un seguit d'orientacions útils per implementar la metodologia del treball per projectes i per usar les TIC a l'aula.
\end{abstract}

ENTREVISTADORA: Són evidents els punts forts de la teva proposta. Quin creus que va ser el que va fer que La Fundación Telefónica la triés com a guanyadora?

CANALS: Això potser ho hauríem de preguntar als membres del jurat, però de la valoració que en van fer, en destaco un fet que em sembla imprescindible en la programació per projectes: les eines tecnològiques estan sempre en funció del contingut curricular que es vulgui treballar i no a l'inrevés. Cal anar molt en compte perquè les TIC són molt atractives i ens faciliten, entre d'altres, la motivació, la creació, revisió i la difusió de manera ràpida i molt visual, però no ens han de fer perdre l'objectiu del treball que és, en aquest cas, donar eines gramaticals, textuals $\mathrm{i}$ procedimentals als alumnes per tal de fer millors textos. En tot moment tenia present que el que fèiem era un treball de llengua i que ens servíem de la tecnologia en funció de l'objectiu d'ensenyament-aprenentatge previst. 
Un altre aspecte que també van valorar va ser la idea a partir de la qual es va generar tot el projecte, la carta que els alumnes van escriure i van llegir a la pròpia besàvia encara que no l'haguessin coneguda mai. Aquesta barreja de realitat i irrealitat, d'imaginació i d'implicació personal va donar un punt imaginatiu i personal al projecte $\mathrm{i}$ va facilitar que els alumnes manifestessin idees, impressions, emocions i sentiments mentre feien un treball de llengua.

ENTREVISTADORA: Ens expliques com va sorgir el projecte?

CANALS: Hi ha diferents factors que junts van propiciar el desenvolupament del projecte. D'una banda, el curs anterior havia fet un treball amb els alumnes per treballar la carta com a gènere textual i m'havia inventat un parent imaginari, descendent d'un besavi que havia emigrat a Mèxic després de la guerra civil. Aquest parent, un jove de l'edat dels alumnes, els escrivia una carta, que vaig llegir a classe, per dir-los que volia conèixer com eren els descendents dels familiars que s'havien quedat a Ripollet. Aquesta situació va plantejar alguns problemes perquè l'origen de les famílies dels alumnes és molt variat i aquesta situació no s'adaptava a tots els alumnes, ja que alguns no tenien besavis que haguessin viscut la guerra o que fossin del poble. Va ser en aquest moment quan vaig començar a buscar una situació comunicativa que pogués ser versemblant per a tots els alumnes, fos quin fos el seu origen.

Escrivint a la besàvia teníem el mateix punt de partida per a tots els alumnes i a la vegada valoràvem les seves famílies i ajudàvem, també, al seu creixement personal i a l'enfortiment dels vincles familiars. Els alumnes van tenir l'oportunitat d'investigar, a través de les entrevistes, sobre el passat de la pròpia família i a la vegada de tota una generació. Tot això va donar un valor $\mathrm{i}$ un reconeixement als seus avantpassats fins al punt que alguns alumnes van manifestar que era un dels aspectes que més els havia emocionat.

D'altra banda, és realment bo que algunes de les experiències d'aula siguin molt properes als alumnes per tal que la seva implicació sigui més gran. La carta a la besàvia era, doncs, el marc idoni per a una activitat més completa, que es podia adaptar a les individualitats dels alumnes. I així és com va sorgir la idea d'escriure a una de les seves besàvies. La situació no era real, evidentment, perquè la carta mai va arribar al destinatari, però sí que els va resultar 
versemblant. Aquest era el marc que va ajudar que l'alumne fos el protagonista i se sentís motivat per portar a terme l'objectiu del projecte, que no era altre que la millora de les habilitats lingüístiques de l'alumne en llengua catalana.

ENTREVISTADORA: Quins són els reptes més importants que vas haver de superar durant aquesta experiència educativa?

CANALS: Són diversos els reptes que vam haver de superar. Per començar, el fet de treballar amb els alumnes per projectes no sempre és fàcil perquè estan molt acostumats a escoltar i a fer exercicis. I el treball per projectes demana una implicació important per part de l'alumne.

El nombre d'alumnes no va ser cap problema perquè eren grups prou reduïts, de poc més de 20, però és cert que fer-ho amb un nombre elevat d'alumnes presenta més dificultats i exigeix una organització molt clara i un interès gran per part dels alumnes, que no sempre hi és.

Les TIC sí que es van convertir en un escull difícil de superar. Els alumnes utilitzaven el seu ordinador a l'aula i al principi costava evitar que l'utilitzessin per a altres finalitats no educatives. A més, la connexió a Internet no sempre funcionava i, per tant, sovint havíem de canviar les activitats per a poder continuar treballant. I pel que fa al descobriment i utilització de noves eines al principi van ser menys autònoms del que preveia fins que els vaig proporcionar alguns manuals bàsics que els ajudessin en la utilització de les diferents plataformes o programes. Calia que les explicacions a classe fossin mínimes i que cada alumne o grup d'alumnes pogués anar seguint el manual en el moment que li fes falta.

Hi va haver una dificultat afegida. Com que els alumnes treballen al seu ritme, sovint tenien dubtes que s'havien de solucionar al moment i les explicacions havien de ser molt individualitzades. Tot i que fossin poc més de vint alumnes, no hauria donat l'abast a ajudar-los si no fos perquè van cooperar entre ells. Vam establir diferents sistemes per afavorir l'aprenentatge entre iguals, però el que millor va funcionar va ser dividir la classe en grups de suport per tal que els alumnes recorreguessin als propis companys en cas de dubte. Mentre treballaven a classe es va insistir molt que cooperessin entre ells, encara que no fossin del mateix grup. Hi ha alumnes que són molt hàbils en activitats educatives tradicionals però que no ho són 
en d'altres i a l'inrevés. Donar la possibilitat que uns i altres compartissin el que sabien fer bé, va fer que alguns alumnes poc valorats habitualment veiessin reconegudes les seves habilitats. També durant la classe vam facilitar la consulta i ajut entre tots. Només m'havien de consultar en cas que no es posessin d'acord o no trobessin la solució. D’aquesta manera podia fer atenció individualitzada quan feia falta sense que hi hagués una interrupció constant.

ENTREVISTADORA: I vas haver de modificar el disseny inicial de la programació?

CANALS: En un projecte complex com aquest, és difícil preveure abans de portar-lo a terme totes les activitats i tot el que podrà donar de sí. Les línies generals han d'estar ben programades, però hi ha d'haver cert marge perquè es pugui modificar. Quan ets a l'aula amb els alumes comproves realment si el que havies previst funciona i de vegades s'obren noves possibilitats que cal explorar en funció dels objectius previstos.

El disseny inicial es va modificar perquè, de fet, el projecte es va anar ampliant. Per exemple, en un principi només estava previst escriure la carta, no la biografia, però a partir del moment en què els alumnes van fer les entrevistes a la família per obtenir informació sobre la besàvia, redactar la biografia es va presentar com a imprescindible. Els alumnes també van fer-hi aportacions durant la classe, a través dels taulers digitals o a través del fòrum que vam obrir, que es van tenir en compte.

ENTREVISTADORA: Ens expliques alguna anècdota?

CANALS: N'hi va haver més d'una. Per exemple, un alumne que repetia curs i que no tenia cap interès a fer res només començar va dir: “Quin rotllo, profe!”. Però, sorprenentment, es va posar a fer la feina. Quan la feina estava avançada es va encallar i vaig demanar a una companya que li donés un cop de mà. Finalment va ser un dels primers a acabar tota la feina i, a més, em va sorprendre per la seva qualitat.

Una altra alumna, de llengua materna castellana i molt reticent a tot allò que estigui relacionat amb la llengua catalana, explicava, orgullosa, com la seva mare havia plorat en sentir 
la lectura de la carta que ella havia enregistrat. I a més, la seva mare s'havia emocionat perquè l'havia llegida en català!

Recordo una alumna que, tota decidida, em va dir que havia decidit gastar menys perquè s'havia adonat que la seva besàvia havia hagut de viure amb molt poc i que ella realment no necessitava tantes coses.

Escoltar com una alumna m'agraïa en la carta que havia escrit i llegit a la seva besàvia que li hagués donat l'oportunitat de conèixer-la va ser un moment que va recompensar molts esforços. Molts alumnes van manifestar que els hauria agradat molt poder parlar amb ella. I en conjunt, tots van mostrar admiració per les seves vides i per la valentia amb què van enfrontar-se a situacions ben dures tant familiars com per les guerres que havien hagut de viure.

ENTREVISTADORA: Han anat sorgint reflexions molt útils, per acabar; pots facilitar algunes orientacions pràctiques per a tots aquells docents que ja fan servir, o volen començar a aplicar la metodologia del treball per projectes?

CANALS: Potser és important no voler ser excessivament ambiciosos. De vegades quan veiem altres projectes ens espantem perquè hi veiem una implicació massa gran o perquè són molt vistosos. Petits projectes poden ser igual o més efectius si tant el professorat com l'alumnat s'hi senten còmodes i tenim clar què volem obtenir i com ho volem treballar. I com a orientacions, potser aquestes:

Integrar el treball de llengua en una proposta més àmplia propera als alumnes per tal que les activitats que es facin siguin properes a la seva realitat i, per tant, rellevants per a ells.

Procurar que el coneixements gramaticals tinguin un sentit en funció del textos que s'hagin de redactar i no siguin l'objectiu en ells mateixos.

Fer reflexionar l'alumne sobre el que està aprenent, fer-ho explícit i sistematitzar-ho per fer connexions amb els altres coneixements que tenen.

Fomentar la col-laboració entre ells a través dels grups o en el conjunt de la classe, és a dir, donar veu als alumnes, que sovint tenen més idees de les que manifesten. 
Afavorir que vegin l'error com a oportunitat d'aprenentatge, valorar positivament els encerts i oferir propostes de millora.

Respectar la diversitat en els ritmes d'aprenentatge i per tant establir un marge ampli que permetin que cada alumne avanci de manera individualitzada. La redacció en documents compartits i la cooperació entre companys ho fan possible. Ara bé s'ha de facilitar que aquest intercanvi de coneixements es faci dins l'aula mateix en el moment que fa falta i, per tant, tenir marge perquè hi hagi cert moviment dins l'aula. Si ens fa por que alguns acabin molt de pressa, cosa que passa sovint, es poden tenir a punt activitats alternatives complementàries.

Obtenir un producte que es pugui ensenyar o comentar i que surti de les parets de l'aula perquè motiva l'alumne i dóna un sentit real a l'activitat que porta a terme.

Fer servir les TIC quan realment afavoreixin la implicació de l'alumne o la planificació, redacció, revisió o difusió.

ENTREVISTADORA: Alguna reflexió final?

CANALS: Portar a terme un projecte com aquest comporta una gran implicació tant per part dels alumnes i com per part de la professora. Aquests alumnes estan poc acostumats a treballar d'aquesta manera i els costa una mica trencar la inèrcia que tenen i ser molt més actius del que són habitualment. Ara bé, si l'activitat és realment motivadora és més fàcil que els alumnes s'hi incorporin amb facilitat.

De vegades, la feina de la professora supera excessivament l'hora de classe i és difícil posar-hi un límit. Compartir documents amb els alumnes és molt útil pedagògicament perquè et permet comunicar-te amb un alumne que té una dificultat concreta i en el moment que la té, però això té el seus perills, ja que de vegades l'alumne espera que en qualsevol moment del dia se li responguin els dubtes i acabes permanentment connectada. Per evitar que això sigui un problema, es poden establir les condicions en les quals es revisaran les tasques dels alumnes o es resoldran dubtes a través de la xarxa fora de classe. En aquest projecte això va ser realment un problema, però vista l'experiència, en un projecte posterior el plantejament d'unes normes mínimes van minimitzar molt aquest risc. 
Repetir un projecte té els seus avantatges perquè l'experiència et permet millorar-lo i, a la vegada, rendibilitzes tot l'esforç que hi has dedicat. Ara bé, cal ser conscients que hi ha un factor que canvia cada vegada, l'alumnat, que és únic i irrepetible. El que funciona amb un grup sovint no acaba d'anar bé amb un altre. Un projecte revisat és, habitualment, sensiblement millor que l'anterior, però hi ha algunes emocions o sentiments que li donen un toc especial que no sempre es tornen a produir o bé que es produeixen de manera diferent. I si el que volem és transferir-lo a un altre docent, cal que el projecte estigui molt ben programat perquè sigui fàcil de portar-lo a terme. I és convenient fer-ho perquè així compartim esforços, experiències i coneixements. Ara bé, cal que el docent se'l cregui i se'l faci seu amb les adaptacions que li semblin adequades. El projecte no serà idèntic però el professor hi pot aportar aquell toc personal que el farà realment especial. I quan un professor es creu un projecte és molt més fàcil que pugui transmetre l'entusiasme als alumnes.

Alguns cops hi ha el perill que l'alumne es quedi en la part vistosa del projecte i que tingui la sensació que no està aprenent. És ben cert que no està estudiant de la manera tradicional, però el que està fent ho està experimentant, no memoritzant. Si ho acompanyem de la reflexió i de la sistematització del que s'està treballant l'aprenentatge serà, probablement, més significatiu. I, a més, l'alumne en serà més conscient. I en el cas del treball de la gramàtica en funció dels textos que es redactaran i no com a objectiu en ella mateixa, això encara té més sentit.

Treballar per projectes no és, evidentment, l'única manera de treballar, però té avantatges evidents i és perfectament combinable amb altres tipus d'activitats d'ensenyament-aprenentatge.

I per acabar, s'aprèn d'un projecte a l'altre sobretot, si reflexionem i escrivim sobre allò que ens ha funcionat bé o allò que es podria millorar.

ENTREVISTADORA: Moltes gràcies. 


\section{Referències Bibliogràfiques}

Canals i Palau, M. (2007a). Altre cop escriure? Un altre cop corregir? Perspectiva escolar, 313 : 84-87.

Canals i Palau, M. (2007b). És realment efectiva la nostra correcció. La fem plegats? Perspectiva escolar, 320: 61-64.

${ }^{1}$ L'experiència es pot consultar a:http://estimadabesavia.blogspot.com.es/

\section{Referencies de l'autora}

Aida Guillén Onandia és llicenciada en Filologia Hispànica i ha cursat el Màster en Recerca en Didàctica de la Llengua i la Literatura de la Universitat Autònoma de Barcelona. Treballa com a professora de castellà i d'anglès al Departament d'Ensenyament de la Generalitat de Catalunya.

Email: aida.guillen@e-campus.uab.cat

Per a citar aquest article:

Guillén Onandia, A. (2013). Una carta a la besàvia: continguts, reflexió i sistematització a la classe de llengua. Algunes de les claus del treball per projectes. Entrevista amb Mercè Canals i Palau. Bellaterra Journal of Teaching \& Learning Language \& Literature, 6(3), 70-77. 